1891-in spite of the fact that over 1,000 children were treated by the serum method in the hospitals, beside numerous cases in private practice. Adding the number of deaths that occurred between November 24 and January 1, the mortality of Berlin from diphtheria in 1894 exceeded that of the year 1891 by about 600 , or over 25 per cent.

Rumpf, of Hamburg, states that better results are obtained in the hospitals there by other methods.

Virchow and Baginsky have expressed themselves in favor of the serum-therapy, but inasmuch as the opinion of the former is based upon certain results said to have been obtained by his assistants during a few weeks in the summer of 1894 , while he was absent on his vacation-and inasmuch as the latter entirely ignores and defies mortality statistics-their opinions upon this subject can be of little or no value. (See Proc. Berlin Medical Society, Nov. 28, Dec. 7, 12, 1894.)

I will exclude all data coming from Behring, Aronson and others personally interested in the manufacture and sale of antitoxin serum. As a rule, medical men in Europe are very conservative regarding this new therapy-as they have not yet recovered from the humiliating effects of the "tuberculin swindle," which originated in the same quarters.

So far, nothing has appeared in the American medical press which would indicate that medical men in this country are familiar with the cardinal principles underlying this subject-and I would advise them to "look before they leap," as perhaps neither "they" nor the "American public" are ready to accept these principles when fully understood.

These principles were exposed by Binz in 1883 at the BudaPesth Congress for Internal Medicine, when he said: "Our future therapeutic efforts in infectious diseases must be toward 'Den lebenden organisms zu entgiften." (To poison the organism, as it were.)

I take issue with Binz and his followers on this doctrine and I believe that the majority of the American medical profession will continue in the future as they have done in the past-to eliminate the contagium at the bedside. "Den lebenden organisms nicht zu entgiften-wollen." Respectfully. Chas. G. Kuhl.Man, M.D.

\section{Answer to Dr. Rogers.}

New YoRk, June 10, 1895.

To the Editor:-Dr. Rogers' attack upon Koch's demonstration of the causation of cholera, in the Journal of June 8 , is rather amusing to the medical man of to-day. While believing that he will receive answers more able than mine, I take the liberty of calling his attention to a few errors in his statement.

In the first place, Koch did not "fancy" that the comma bacillus was the cause of cholera; it had to be present in every case of cholera, it had to be capable of cultivation in artificial media in pure culture, and it had to produce the disease whenever inoculated, before he was willing to identify it as the cause. Unfortunately, the inoculation experiments do not depend alone upon results obtained in the lower animals, for several bacteriologists have themselves been infected while working with this organism.

In the second place, while comma-shaped organisms are universal, as the Doctor states, the comma bacillus of Koch is neither universal nor harmless. If the shape of microorganisms alone were sufficient to differentiate them, what a simple easy study would be the science of bacteriology! Dr. Koch has never asserted, to my knowledge, that the cholera bacillus is frequently present in water from all sources, although any up-to-date physician knows that curved bacilli are frequently present. All cholera germs are curved bacilli, but all curved bacilli are not cholera germs.

The experiments of Drs. Pettenkofer and Emmerich, as alluded to in the letter, prove nothing, for the following (and other) reasons:
1. Koch and many other observers have shown that acids readily kill this organism; we can easily understand, therefore, how the healthy acid gastric juice of the two physicians protected them from infection. Drinking cholera broth does not necessarily imply infection; it only makes infection possible. The liquid stools mentioned can be produced by toxins isolated from old cultures, without any bacilli being present.

2. Organisms grown on artificial media for many generations are very apt to lose their virulence, even though they may have been very virulent in the first few cultures.

In conclusion, I would hardly advise Dr. Rogers to repeat the experiments of Pettenkofer and Emmerich, as such a communication as he has given us, in defiance of modern scientific research, might indicate that his gastric juice had alkalin tendencies! Yours respectfully, Walter G. Hudson, M.D.

\section{A Card from Secretary Atkinson.}

Philadelphia, June 4, 1895.

To the Editor:-Your explanation of the inability to send the Jovrsal to the new members does me great injustice. As I wrote you, not any of the credentials nor papers of the Registration Committee have yet reached me. All were sent directly to Dr. Newman, our Treasurer. Had I had the list or my own private index, made especially to prevent this, I would have had my share done at once. For this reason, I ask you to do me the justice to announce in the JourNAL the fact that all the papers were sent at once to Chicago. I am getting letters on this subject constantly, and it is important that I should be set right before the profession. Please do me this favor at once.

$$
\text { Yours very truly, }
$$

Wm. B. Atikinson.

\section{Literature on the Dual Brain.}

Str. Lours, June 4, 1895.

To the Editor:-I have read with interest your editorial on the "Dual Brain," in a recent number of the Jourval. Please inform me how I can procure Dr. Bruce's article on this subject, also the writings of Holland and Wigand, and Brown-Séquard.

Fayette C. Ewing, M.D.

Axswer:-Dr. Wigand, "Duality of Mind," Lancet, 1844 ; Sir Henry Holland, "Chapters on Physiology of Mind," 1852; Brown-Séquard, Toner Lecture, 1877 ; L. C. Bruce's article in Brain, Spring No., 1895.

\section{Exact Address of Association Treasurer.}

Coronado, Cal., June 1, 1895.

To the Editor:-Will you please insert in our Journas the exact place of residence of the Treasurer of the Association, that members may know just where to send dues.

F. W. Tond, M.D.

Axswer:-Henry P. Newman, M.D., 36 Washington Street, Chicago, Ill.

\section{SOCIETY NEWS.}

American Academy of Railway Surgeons, Meeting of the Publication Committee.-Pursuant to the call of the President, Dr. C. K. Cole, Helena, Mont., Drs. C. B. Kibler, Corry, Pa ; W. J. Galbraith, Omaha, Neb.; R. Harvey Reed, Columbus, Ohio; C. M. Daniels, Buffalo, N. Y., and Webb J. Kelly, Galion, Ohio, met June 1, at Galion, Ohio, to arrange the preliminary work for the coming session of the American Academy of Railway Surgeons. After considerable discussion, the date of the meeting was set for September 25,26, and 27. This was thought advisable on account of the previous date conflicting with those of other prominent associations; and 